\title{
Uso de Entrevistas On-Line no Método de Explicitação do Discurso Subjacente (MEDS)
}

\section{Use of Online Interviews in the Underlying Discourse Unveiling Method (UDUM)}

\author{
Ana Maria Nicolaci-da-Costa*, Daniela Romão-Dias \& Flávia Di Luccio \\ Pontifícia Universidade Católica do Rio de Janeiro
}

\begin{abstract}
Resumo
Tradicionalmente, tal como outros métodos qualitativos que usam entrevistas, a coleta de dados do MEDS é realizada em encontros presenciais que têm como modelo as conversas cotidianas em contextos informais. Com o advento da Internet, grande parte dessas conversas migrou para os ambientes de troca instantânea de mensagens on-line, que se popularizaram rapidamente. $\mathrm{O}$ argumento central deste trabalho é o de que, desde então, a coleta de dados por meio de entrevistas on-line, baseadas no modelo das conversas cotidianas informais que também ocorrem on-line, se tornou um procedimento de pesquisa sério e viável. São, portanto, discutidas as especificidades, requisitos, vantagens e desvantagens desta nova forma de entrevista. São, ainda, revelados o histórico, os raciocínios e as necessidades que a legitimam.

Palavras-chave: MEDS; métodos qualitativos; entrevistas on-line; conversa informal.

Abstract

Traditionally, as in other qualitative methods that use interviews, data collection in UDUM is done in face-toface encounters based on the model of daily conversations in informal contexts. With the advent of the Internet, a large part of such conversations migrated to online environments of instant message exchanges, which soon became widely popular. The main argument of this paper is that, since then, data collection through informal online interviews, which have equally informal online daily conversations as a model, has become a serious and viable research procedure. Specificities, requisites, advantages and disadvantages of this new form of interview are, therefore, discussed. The history, reasoning and needs that legitimate it are also revealed.

Keywords: UDUM; qualitative methods; on-line interviews; informal conversation.
\end{abstract}

O mundo mudou muito, e a olhos vistos, nesta virada de milênio. Entre os diversos fatores responsáveis por essa mudança, estão: a Revolução Digital; a nova organização em rede de praticamente tudo (sociedades, instituições, empresas, grupos de solidariedade, relacionamentos, etc.); a crescente mobilidade (real e/ou virtual) de grandes parcelas da população mundial; a volatilidade ou fluidez de muitos elementos da vida social e individual (a começar pelo próprio capital); o incremento acentuado do processo de globalização, etc. Muitas das coisas que tínhamos como estáveis e sólidas ao longo do século XX (a exemplo da soberania dos Estados-nação; do emprego da mão-de-obra local; dos direitos trabalhistas; dos sindicatos fortes) provaram ser frágeis ou passageiras. Muitas certezas deram

\footnotetext{
* Endereço para correspondência: Pontifícia Universidade Católica do Rio de Janeiro, Departamento de Psicologia, Rua Marquês de São Vicente, 225, Gávea, Rio de Janeiro, RJ, Brasil, CEP 22543-900.E-mail: ananicolaci@pq.cnpq.br As autoras agradecem o apoio do Conselho Nacional de Desenvolvimento Científico e Tecnológico (CNPq), sob a forma de bolsa de produtividade para a primeira autora, de doutorado para a segunda e de mestrado para a terceira. Agradecem também à Fundação de Amparo à Pesquisa do Estado do Rio de Janeiro (FAPERJ) a bolsa de doutorado concedida à terceira autora.
}

lugar ao completamente desconhecido. No contexto geral, passou a vigorar um paradoxo: um estado de mudanças constantes que gera sucessivas levas de indagações.

Nesse quadro mundial, saber indagar se tornou de crucial importância. A necessidade de explorar os diversos aspectos das transformações que não param de ocorrer provocou uma profunda transformação no cenário das pesquisas nas ciências sociais e humanas (Jodelet, 2003). Nestas, juntamente com as mudanças tecnológicas e sociais acima mencionadas, a passagem do século XX para o XXI presenciou a emergência de um "campo" autônomo da pesquisa qualitativa, acontecimento inédito principalmente no universo acadêmico anglo-saxão (Denzin \& Lincoln, 2000; Nicolaci-da-Costa, 2007). E as novidades não param aí. Outro aspecto singular desse campo é o fato de ele ser composto por tal variedade de métodos que leva alguns autores a declararem que "nunca houve tantos paradigmas, estratégias de investigação, ou métodos de análise dos quais o pesquisador possa lançar mão" (Denzin \& Lincoln, 2000, p. 18).

Entre todos esses métodos qualitativos encontram-se aqueles que fazem uso de entrevistas para a coleta de dados (Gomes, 1997; Maxwell, 2005; Rubin \& Rubin, 2005; Seidman, 1998; Taylor, 2001; Turato, 2003; Weiss, 1994, etc.). Tal como os demais métodos que pertencem ao novo 
campo da pesquisa qualitativa, eles são criados e adotados por pesquisadores que têm uma convicção em comum: a de que a adequação de um método depende dos objetivos da pesquisa. Na visão desses pesquisadores, diferentes objetivos podem requerer diferentes métodos, procedimentos e/ou instrumentos de coleta de dados, pois cada um destes apresenta um tipo de sensibilidade distinto que pode ou não ser compatível com um objetivo específico. Como os objetivos das pesquisas humanas e sociais são numerosos também são numerosos os métodos.

Dentre os métodos qualitativos que usam entrevistas, um - o Método de Explicitação do Discurso Subjacente, MEDS (Nicolaci-da-Costa, 2007) - vem se mostrando particularmente sensível para explorar as complexidades das transformações de cunho psicológico geradas pelas muitas transformações que vêm ocorrendo nas últimas décadas. E essa sensibilidade se deve em grande parte à forma pela qual o MEDS faz sua coleta de dados. Resumindo de forma compacta o que foi detalhadamente apresentado em um artigo recente (Nicolaci-da-Costa, 2007), essa coleta é tradicionalmente realizada por meio de entrevistas presenciais que - e esta é uma das grandes preocupações do MEDS devem se aproximar o máximo possível de conversas informais cotidianas. Para garantir essa informalidade, o MEDS adota diversos procedimentos como, por exemplo: (a) ter como base um roteiro de itens a partir do qual as perguntas sejam formuladas durante a própria entrevista de modo que não soem artificiais; (b) respeitar o fluxo do raciocínio do entrevistado por meio da aplicação flexível desse roteiro (o que significa dizer que a ordem das perguntas, por exemplo, pode ser alterada); e (c) conduzir as entrevistas em contextos informais nos quais os entrevistados se sintam à vontade.

O MEDS considera esse último ponto extremamente importante para que os entrevistados se sintam relaxados e seu discurso flua com espontaneidade. Em decorrência disso, grande ênfase é dada à escolha de locais que lhes sejam familiares.

Feita essa breve exposição de como o MEDS prevê que seja executada a coleta de dados, é chegado o momento de esclarecermos o que pretendemos fazer neste artigo.

Pretendemos dar um passo adiante. Sempre respeitando a já mencionada máxima que rege as pesquisas qualitativas contemporâneas - a de que, para cada objetivo, deve-se lançar mão de métodos, procedimentos e/ou instrumentos de coleta de dados que apresentem sensibilidade compatível - pretendemos mostrar como o MEDS pode ser expandido para se tornar sensível a novas demandas de pesquisa e/ou novos contextos de vida. Com esse propósito, serão descritos alguns novos procedimentos e instrumentos de coleta de dados.

Antes, porém, cabe apresentarmos a fonte inspiradora do passo adiante que vamos expor bem como o raciocínio e os fatos que o justificam. Começaremos com uma breve descrição da primeira: o conhecido artigo "The logic of non-standard English" (1972), de autoria do lingüista norte-americano William Labov.

\section{O Revolucionário Trabalho de Labov}

Nos conturbados dias de luta pela igualdade racial nos Estados Unidos, na também conturbada década de 1960, Labov (1972) contestava frontalmente as afirmações então bastante difundidas na sociedade norte-americana de que os negros eram inferiores aos brancos porque eram "cultural e lingüisticamente privados", ilógicos, monossilábicos, etc.

Naquela época, tais afirmações eram vistas como respaldadas em resultados de pesquisas científicas de cujos métodos, procedimentos e instrumentos de coleta de dados Labov discordava. Para combatê-los, bem como para a eles criar alternativas, Labov inovou. Fez uso de seu profundo conhecimento da comunidade negra do Harlem, cuja cultura é bastante verbal, e a ele aliou bom senso, sensibilidade e criatividade. Como resultado, alterou vários dos procedimentos de pesquisa então vistos como firmemente estabelecidos e teve seu artigo alçado à categoria de um "clássico".

Inspecionemos algumas dessas alterações: (a) ao invés de selecionar sua amostra de acordo com padrões mais ou menos rígidos envolvendo diferentes combinações de fatores como sexo, idade, ocupação, classe social, etc., Labov recrutou sujeitos que, segundo ele, participavam da cultura vernacular das ruas e nada mais; (b) não tentou fazer emergir o discurso de seus entrevistados em locais com os quais eles estavam pouco familiarizados e nos quais se sentiam pouco à vontade (como, por exemplo, salas ou laboratórios de Universidades), então vistos como os mais adequados por serem considerados "neutros". Pelo contrário, realizou as entrevistas no próprio bairro de residência dos entrevistados (o Harlem) e, pelo menos em um caso, no próprio quarto do entrevistado; (c) abandonou o uso de testes padronizados (então amplamente utilizados); (d) tentou fazer com que a entrevista se tornasse menos intimidante para os entrevistados (adolescentes negros) através da redução da assimetria entre entrevistador e entrevistado bem como do estabelecimento de uma situação informal que mais se assemelhava a um bate-papo entre amigos (o que então era visto como pouco científico). Para isso, fez uso de um entrevistador negro, também morador do Harlem, que conhecia os entrevistados e que, para superar ainda outros obstáculos e inibições, fez a entrevista com duplas de amigos na casa de um deles.

Como resultado, Labov pôde mostrar uma visão completamente diferente da cultura negra e das capacidades intelectuais e lingüísticas de seus membros.

"The logic of non-standard English" foi escrito há quase quarenta anos, mas seus vários ensinamentos continuam sendo atuais e relevantes. Dentre eles, destacamos dois. O primeiro é o de que fazer ciência é tentar conhecer aquilo que não se conhece e de que esse "conhecer aquilo que não se conhece" não raro passa pelo como tentamos conhecê-lo. Já o segundo se refere especificamente a esse como. O trabalho de Labov torna evidente que, para conhecermos um ser humano, uma cultura ou uma língua a 
partir de uma visão "de dentro" - ou seja, pelo que eles são e não pelo que parecem ser para quem está "de fora" - é necessário sermos sensíveis e, por vezes, pouco ortodoxos. Isso porque elaborar formas que possibilitem a emergência de suas características sem obstáculos ou preconceitos (coisa que é bastante conhecida por historiadores e antropólogos) não é tarefa trivial.

\section{Outro Tempo, Outro Contexto, mas Necessidades Análogas}

O trabalho de Labov acima descrito exerceu muita influência no desenvolvimento do MEDS e lhe serve de modelo até os dias de hoje (Nicolaci-da-Costa, 2007). Durante muitos anos, ainda sem seu recente nome de batismo, as primeiras versões do MEDS guiaram a realização de diversas pesquisas (como, por exemplo, Nicolacida-Costa, 1987; Rocha-Coutinho, 1994) nas quais havia a preocupação constante de que as entrevistas - então sempre presenciais - fossem realizadas em horários e locais informais escolhidos pelos próprios entrevistados (contanto que esses lugares fossem silenciosos de modo a permitir o uso do gravador). O intuito era sempre o de que os participantes das pesquisas se sentissem à vontade como em uma conversa cotidiana.

A partir de meados da década de 1990 (quando teve início a rápida difusão da rede mundial de computadores), no entanto, surgiram novas possibilidades e necessidades. A difusão e popularização da Internet fizeram com que milhões de pessoas ao redor do mundo passassem a usar novas formas de comunicação interpessoal, geralmente gratuitas uma vez que se tenha acesso à Internet e na maior parte das vezes por escrito. Algumas delas são assincrônicas e outras sincrônicas. Nas assincrônicas, a troca de mensagens entre interlocutores ocorre com intervalos de tempo não previsíveis. É o caso dos programas de e-mail, dos fóruns de discussão, etc. Já nas sincrônicas, como o ICQ, o Google Talk, o AOL Instant Messenger (AIM), o Yahoo! Messenger, o MySpace IM, o MSN Messenger e congêneres, a troca de mensagens entre interlocutores acontece instantaneamente, ou seja, em tempo real. ${ }^{1}$

Para estes novos ambientes, nos quais a interação é instantânea, migrou grande parte das conversas antes presenciais ou telefônicas. A conversa on-line por escrito passou a ser tão apreciada que se difundiu rapidamente tendo hoje se tornado corriqueira. E é interessante observar que essa popularidade foi conquistada apesar da existência de programas de voz, como o Skype, nos quais as conversas on-line são análogas às conversas telefônicas (com a grande diferença de que não são tarifadas). Estes últimos, pelo menos até agora, não tiveram a mesma aceitação e o mesmo sucesso ${ }^{2}$.

Todas essas mudanças tiveram um grande impacto sobre os procedimentos de coleta de dados do MEDS. À semelhança do que fazia seu antecessor do século XX, o pesquisador do século XXI que lança mão do MEDS continua a procurar deixar seus entrevistados à vontade como numa conversa cotidiana. Para isso, continua a procurar ambientes naturais com os quais tanto ele mesmo quanto seus entrevistados estejam familiarizados. Só que, diferentemente do que acontecia antes do final do século XX, esse pesquisador se depara com o fato de que vários desses ambientes naturais deixaram de ser físicos. Muitos passaram a ser virtuais.

Como conseqüência, impõe-se o seguinte raciocínio. Se esses são os novos ambientes naturais nos quais acontecem muitas das conversas informais nos nossos dias, é importante que aprendamos a explorá-los e a usá-los quando tal uso for adequado, ou mesmo necessário, para os nossos objetivos de pesquisa.

Por esse motivo, desejamos apresentar aos nossos leitores outro tipo de entrevista que, novamente dependendo do objetivo da pesquisa, vem sendo realizado dentro do escopo do MEDS, sem prejuízo para seus princípios e características gerais: a entrevista on-line em tempo real levada a cabo nos ambientes virtuais de comunicação instantânea.

A introdução de um novo instrumento de coleta de dados, no entanto, não é tão simples quanto pode parecer à primeira vista. Tal como um sistema é alterado quando um de seus elementos é modificado, o conjunto de procedimentos que caracteriza um determinado método também sofre modificações quando um instrumento é substituído por outro. Por esse motivo, retomaremos brevemente as diferentes fases do MEDS discutidas em Nicolaci-daCosta (2007), assinalando, em cada uma delas, o que é mantido e o que muda quando optamos por entrevistas on-line.

Antes de assim procedermos, no entanto, gostaríamos de dizer algumas palavras sobre os tipos de pesquisa que permitem a utilização de entrevistas on-line e também sobre os tipos de pesquisa que requerem sua utilização.

\section{Quando as Entrevistas On-Line são Adequadas, Desejáveis ou Necessárias \\ Independentemente dos objetivos da pesquisa, uma condição é indispensável para a realização de entrevistas on-line, a de que entrevistados e entrevistadores estejam intimamente familiarizados com os ambientes nos quais elas serão conduzidas, ou seja, quando para eles esses am-}

${ }^{1}$ Por isso, são genericamente chamados de programas de Instant Messaging, ou IM - (Crystal 2006). Os programas de IM aqui citados são apenas alguns dos mais difundidos e usados na Rede. Ainda existem muitos outros, o que atesta sua enorme popularidade.

\footnotetext{
${ }^{2}$ Os programas de voz como o Skype tendem a ser usados prioritariamente para chamadas distantes, como as interestaduais ou internacionais, cujas tarifas telefônicas são muito altas. Diferentemente dos programas de IM, não fazem parte do uso cotidiano da maior parte dos usuários brasileiros.
} 
Nicolaci-da-Costa, A. M., Romão-Dias, D. \& Di Luccio, F. (2009). Uso de Entrevistas On-Line no Método de Explicitação do Discurso Subjacente (MEDS).

bientes forem sentidos como naturais. Isto posto, vejamos quando elas são adequadas, desejáveis e/ou necessárias.

As entrevistas on-line são adequadas sempre que essa condição básica for satisfeita e o objetivo da pesquisa permitir seu uso. Elas se tornam especialmente desejáveis quando os próprios participantes da pesquisa sugerem que se sentiriam mais à vontade em uma entrevista on-line do que em uma face a face, como aconteceu no caso de Romão-Dias e Nicolaci-da-Costa (2005), quando esta sugestão lhes foi dada por uma entrevistada durante um encontro presencial.

Pode-se pensar que entrevistas on-line sejam particularmente apropriadas para o estudo de temáticas diretamente ligadas à Internet. Em parte isso é verdadeiro, como mostram, entre outros, os trabalhos de Di Luccio e Nicolacida-Costa (2007) e Ramalho (2005). Essas temáticas, no entanto, também estão sujeitas às limitações ditadas pela condição indispensável de que entrevistadores e entrevistados tenham intimidade com os ambientes de diálogo on-line. Um bom exemplo é a investigação, realizada por Abreu e Nicolaci-da-Costa (2006), sobre como os professores de ensino médio estavam lidando com a entrada da Internet em seu trabalho docente. Dado que esses docentes ainda mostravam resistência à Internet, as pesquisadoras optaram por realizar entrevistas presenciais. $\mathrm{Na}$ realidade, ao menos em princípio, as entrevistas on-line podem ser usadas para investigar qualquer temática desde que seja atendida a condição de que entrevistado e entrevistador estejam familiarizados com os ambientes em que as entrevistas serão realizadas.

Por último, as entrevistas on-line são necessárias quando são o único meio de alcançar os entrevistados. Um exemplo é o trabalho de Di Luccio e Nicolaci-da-Costa (2007), que entrevistaram escritores de blogs que residiam em diferentes lugares do Brasil

\section{As Diferentes Fases do MEDS: O que é Mantido e o que é Alterado}

\section{Fase 1: Seleção da Amostra}

Recrutamento dos Participantes. Existe consenso quanto ao fato de que as pesquisas qualitativas são muito trabalhosas, demandam muito tempo e que, por isso, usam poucos participantes (Rubin \& Rubin, 2005; Taylor, 2001; Weiss, 1994). Como conseqüência, o recrutamento destes, ao invés de randômico, é quase sempre intencional (Maxwell, 2005) e cuidadosamente pensado. Embora tais afirmações sejam feitas em relação às entrevistas face a face, é evidente que também se aplicam às entrevistas on-line.

Ainda no que diz respeito às entrevistas presenciais, mas claramente passíveis de aplicação às entrevistas on-line, os procedimentos para o recrutamento de participantes, embora muito variados, seguem um de dois princípios básicos: a heterogeneidade (Maxwell, 2005; Rubin \& Rubin, 2005; Seidman, 1998; Weiss, 1994) ou a homogeneidade (Maxwell, 2005; Turato, 2003) de características dos participantes.

Tanto nas entrevistas presenciais quanto nas entrevistas on-line, o MEDS tende a buscar a homogeneidade. Esta pode ser de dois tipos: fundamental (uma característica ou experiência importante em comum), ou ampla (como, por exemplo, vários atributos pessoais - idade, sexo, ocupação, classe social, etc. - em comum além da referida característica ou experiência), a partir de critérios pré-estabelecidos em função dos objetivos da pesquisa. Quando utiliza entrevistas face a face, o MEDS freqüentemente privilegia um tipo de recrutamento que possibilita o enquadramento dos participantes naquele que é denominado "perfil de alta definição", construído a partir de tantos critérios quantos sejam necessários para identificar os membros de um grupo social específico. Este perfil de alta definição é de mais difícil adoção nas entrevistas on-line, mas pode continuar a ser empregado quando a realização desse tipo de entrevista for feita a partir de uma seleção off-line de participantes.

No caso de um recrutamento on-line, no entanto, nem sempre é possível, ou mesmo desejável, buscar um perfil desse tipo. E o motivo é que, on-line, as características pessoais dos entrevistados - idade, classe social, nível educacional, local de moradia, etc. - tendem a perder a importância que têm off-line. Isso porque a própria escolha que os entrevistados fazem de determinados tipos de programas, ambientes e recursos, dentre os inúmeros disponíveis, tendem a definir seus perfis de modos mais relevantes e condizentes com uma seleção on-line (as características pessoais podem sempre ser coletadas e usadas como informações adicionais). Bons exemplos são os trabalhos de Ramalho (2005) com freqüentadores do site de encontros Par Perfeito e de Di Luccio e Nicolaci-da-Costa (2007) com escritores de blogs.

Esses critérios de recrutamento têm mostrado ser mais do que suficientes e apropriados para alcançar aquele que é um dos principais objetivos do MEDS, a investigação das inconsistências, conflitos e/ou transformações internas gerados por situações novas. Di Luccio e Nicolaci-daCosta (2007), por exemplo, puderam identificar que, apesar de oficialmente terem criado seus blogs com o objetivo de publicarem textos, serem lidos e interagirem com seus leitores, os escritores de blogs entrevistados tendiam a formar comunidades, interagindo principalmente entre si. Já Romão-Dias e Nicolaci-da-Costa (2005) puderam identificar algumas transformações subjetivas que estão na origem do que pode ser chamado de nova "configuração subjetiva" contemporânea.

Decisões a Respeito do Número de Participantes. Como vimos acima, a adequação do uso de poucos participantes nas pesquisas qualitativas é consensual. Além disso, números de participantes são raramente estipulados a priori na medida em que o principal critério usado para determinar se as entrevistas realizadas são suficientes para a investigação de um determinado assunto é o fenômeno conhecido como "ponto de saturação" (Bertaux, 1980; Seidman, 1998; Turato, 2003). Este ocorre quando, após um certo número de entrevistas, há uma rarefação de informações novas e o entrevistador começa a ouvir (ou ler, no caso das entrevistas on-line) relatos muito semelhantes àqueles que já ouviu (ou leu) feitos por novos entrevistados. Isso ocorre tanto presencialmente quanto on-line. 


\section{Fase 2: A Construção do Roteiro para as Entrevistas}

Tal como no caso da utilização de entrevistas face a face, antes de dar início à coleta de dados nas entrevistas on-line, é necessária a construção do instrumento que servirá de base a essa coleta.

No que diz respeito à construção do roteiro, o MEDS dá às as entrevistas presenciais e on-line o mesmo tratamento. Em ambos os casos é detalhista, pois adota o ponto de vista de que um bom roteiro é indispensável para uma boa pesquisa e estipula diretrizes gerais para sua construção.

Dado que não cabe aqui repetir o que já foi minuciosamente descrito em Nicolaci-da-Costa (2007), seguem-se, resumidamente, as principais dessas diretrizes: (a) os roteiros devem ser estruturados em sua concepção, porém aplicados com flexibilidade; (b) os roteiros devem se inspirar em conversas naturais; (c) para que as perguntas sejam automaticamente adaptadas ao contexto das entrevistas, preservando todas as suas características lingüísticas e extra-lingüísticas naturais, os roteiros devem constar apenas de itens que serão expandidos sob a forma de questões durante as próprias entrevistas. No caso das entrevistas on-line, a formulação das questões deve respeitar todas as formas de escrever características dos ambientes interativos on-line (Crystal, 2006); (d) os itens devem gerar perguntas abertas que comportem qualquer tipo de resposta (como, por exemplo, "O que você acha de x?", "O que y gera em você?); (e) perguntas de esclarecimento e/ ou aprofundamento (como "por quê?”, “como?”, “dá para explicar melhor?", etc.) também devem ser previstas, mas podem ser introduzidas a qualquer momento em que sejam consideradas necessárias; (f) para preservar a naturalidade de uma conversa informal (que nunca é composta somente de perguntas abertas), alguns itens deverão gerar perguntas fechadas (cujas respostas são sim ou não), seguidas de perguntas de esclarecimento e/ ou aprofundamento; (g) itens que geram perguntas mais abstratas - que solicitam opiniões, reflexões, posturas, sentimentos, avaliações, etc. do entrevistado - a respeito de determinados tópicos devem poder ser confrontados com itens que geram informações objetivas a respeito dos mesmos tópicos. Isso porque o contraste entre informações concretas e afirmações abstratas tem o potencial de revelar inconsistências que, por seu turno, podem ser importantes vias de acesso ao discurso subjacente.

De modo semelhante ao que acontece no caso das entrevistas face a face discutidas em Nicolaci-da-Costa (2007), para que se possa chegar a um bom roteiro on-line, sua construção deve ter início em conversas informais, também on-line, sobre a temática a ser investigada sem qualquer tipo de estrutura previamente delineado. Para garantir que o roteiro seja adequado à população alvo, é importante que essas conversas iniciais ocorram com pessoas que apresentem um perfil análogo àquele delineado para os participantes da pesquisa nos ambientes por eles freqüentados. Um primeiro rascunho de roteiro deverá ser elaborado a partir dessas conversas. Esse rascunho, por sua vez, deverá ser testado em outras conversas que já apresentam uma estrutura provisória, as entrevistas-piloto. Muito provavel- mente, a partir dessas entrevistas, o roteiro sofrerá sucessivas modificações e será submetido a novos testes. Quando tudo fluir bem (este é o melhor critério tanto off-line quanto on-line), o roteiro estará pronto.

\section{Fase 3: As Entrevistas}

Semelhanças e Diferenças entre Entrevistas Presenciais e On-Line. Nas entrevistas presenciais do MEDS, tal como em vários outros métodos (Nicolaci-da-Costa, 2007), cada participante é entrevistado individualmente por um único entrevistador. Com algumas alterações que serão discutidas abaixo, o mesmo acontece em suas entrevistas on-line.

Em todos os casos, as entrevistas acontecem em horários negociados entre entrevistadores e entrevistados. No caso das entrevistas on-line, entretanto, esses horários são bem mais flexíveis, podendo mesmo ser pouco convencionais (de madrugada, por exemplo) dependendo de conveniência de entrevistados e entrevistadores.

Todas as entrevistas do MEDS têm como modelo uma conversa informal presencial ou on-line. Por isso, como já foi dito, quando presenciais, elas são sempre conduzidas em lugares com os quais os participantes se acham familiarizados. O mesmo princípio vale para as entrevistas on-line. Estas devem realizadas em um dos ambientes de conversação síncrona que seja comumente freqüentado tanto pelos entrevistados quanto pelos entrevistadores (geralmente a escolha recai sobre aqueles ambientes de troca de mensagens instantânea, como o ICQ, Google Talk, MSN Messenger ou quaisquer outros que estejam entre os mais populares em um determinado período). É imperativo que tanto os entrevistados quanto os entrevistadores dominem a etiqueta, as regras e os códigos do ambiente selecionado bem como adotem o tipo de linguagem escrita e os símbolos nele utilizados, como, entre outros: os smileys ou emoticons (:) (:), as abreviações, tais como $v c$ (você) e $t b$ (também), as grafias que se aproximam dos sons das palavras $($ naum $=$ não, $a k i=$ aqui, poko $=$ pouco, etc. $)($ Crystal, 2006; Nicolaci-da-Costa, 1998).

No caso das entrevistas presenciais, antes de serem entrevistados, os participantes devem assinar um termo de livre consentimento do qual constam informações: (a) sobre os objetivos da pesquisa; (b) sobre os eventuais riscos que ela pode representar para aqueles que dela participam; e (c) sobre o uso que pode ser feito do material coletado. No caso das entrevistas on-line, os participantes recebem as mesmas informações imediatamente antes das entrevistas e são solicitados a dar seu aceite on-line (o que é gravado juntamente com a entrevista como um todo).

No caso das entrevistas presenciais, o MEDS prevê a realização de uma única - contínua - entrevista com cada participante (Nicolaci-da-Costa, 2007). Em princípio o mesmo se aplica às entrevistas on-line. Estas, porém, apresentam uma peculiaridade derivada das características das conversas on-line que têm como modelo. Acontece que as conversas on-line são freqüentemente interrompidas pelos mais diversos motivos e retomadas do ponto onde se deu a interrupção (o que é fácil na medida em que tudo fica registrado no $\log$ das trocas de mensagens). Obviamente, se 
Nicolaci-da-Costa, A. M., Romão-Dias, D. \& Di Luccio, F. (2009). Uso de Entrevistas On-Line no Método de Explicitação do Discurso Subjacente (MEDS).

desejamos que os entrevistados sintam as entrevistas como naturais dentro do contexto do ambiente escolhido, é importante que esse padrão não seja alterado. Alguns entrevistados de Di Luccio e Nicolaci-da-Costa (2007), por exemplo, interromperam as entrevistas por razões diferentes: “. . . vou pegar um café, já volto...!”; “Ops! Desculpas! Tive um imprevisto olímpico...:-D”; "sorry, telefone. vamos lá ....". Em todos os casos, as entrevistas foram natural e bem-sucedidamente retomadas mais tarde. Em franco contraste com as entrevistas presenciais, portanto, as entrevistas on-line podem ser interrompidas e retomadas posteriormente sem que sua qualidade seja comprometida.

Ainda tendo em mente que todas as entrevistas do MEDS têm como modelo uma conversa informal, é necessário registrar outra característica da conversa on-line que deve ser respeitada na entrevista on-line. Acontece que, numa conversa on-line por escrito (o tipo preferido por praticamente todos os usuários), sempre há um intervalo de tempo entre o envio de uma mensagem e o recebimento da resposta à mesma. Esse intervalo, ou lag (Crystal, 2006), ao qual os usuários dos programas de conversação na rede já se habituaram, faz com que nenhuma conversa seja foco exclusivo da atenção dos interlocutores, que quase sempre executam outras tarefas (como checar seu e-mail, continuar trabalhando em um texto do Word, ler mensagens do Orkut, ou se engajar em outras conversas). De modo a dar à entrevista on-line o mesmo clima desse tipo de conversa, esse comportamento dos entrevistados deve ser respeitado pelo entrevistador. Isso, no entanto, não deve acontecer com o próprio entrevistador. Este deve devotar toda a sua atenção exclusivamente para a entrevista que está realizando, tendo o cuidado de esperar que o entrevistado pare de escrever (alguns programas avisam quando isso acontece, enviando mensagens do tipo "xxx está digitando/escrevendo) antes de lhe fazer outra pergunta para evitar a falta de sincronia freqüente nas conversas on-line (Crystal, 2006).

Segue-se um breve exemplo de falta de sincronia. Nele, percebemos que as duas respostas de MARIA BONITA fazem parte de um mesmo depoimento: (a) "sinto q sou uma pessoa informada" e (b) "uma pessoa atualizada". Por conta da falta de sincronia, essas duas afirmações são separadas por intervenções de Carol (a entrevistadora) que se inserem em outras linhas de argumentação na entrevista como um todo.

"Carol diz: e como você se sente estando ligada em tudo?" "MARIA BONITA diz: sinto q sou uma pessoa informada" "Carol diz: e com quantas pessoas você fala ao msm tempo?"

"Carol diz: desculpa, vou ter que pedir pra você tentar mandar o arquivo...."

"MARIA BONITA diz: uma pessoa atualizada".

$\mathrm{O}$ fato de que a conversa é digitada, somado às conversas paralelas e eventuais interrupções faz com que as entrevistas on-line sejam bem mais longas do que as presenciais. Por isso mesmo, o entrevistador deve prestar atenção aos sinais de cansaço de seus entrevistados. Uma boa estratégia para lidar com o cansaço dos participantes é a de, fazendo uso da naturalidade das ocasionais interrupções, já informá-los da possibilidade de pararem a entrevista e continuarem-na mais tarde no início da troca de mensagens on-line (e relembrá-los disso se ou quando houver necessidade). Pode também ser eficaz perguntar diretamente aos entrevistados se eles estão cansados e revelar em que ponto está a entrevista, ou seja, o quanto ainda falta (em geral, quando isso é feito, talvez porque notem que o entrevistador está de fato atento ao que está acontecendo, os entrevistados tendem a não pedir para parar). Todas essas variáveis tornam difícil estimar o tempo médio de uma entrevista on-line.

Por último, como já foi mencionado anteriormente, o MEDS estipula que, tanto nas entrevistas presenciais quanto nas entrevistas on-line, o entrevistador deverá aplicar de forma flexível um roteiro estruturado de modo respeitar o fluxo de associações do entrevistado. Assim sendo, a ordem dos itens pode ser alterada e, dependendo dos pronunciamentos dos entrevistados, alguns itens talvez não necessitem ser transformados em perguntas porque já foram abordados espontaneamente. É interessante observar que essas alterações podem ser mais facilmente executadas on-line do que presencialmente na medida em que o entrevistador tem ao seu dispor tanto o registro escrito da entrevista quanto o tempo de espera da resposta - o lag - para pensar no que fazer. Apesar de todas essas alterações, o entrevistador deve se certificar de que todos os itens do roteiro sejam abordados de modo a viabilizar as análises comparativas previstas pelo MEDS (Nicolaci-da-Costa, 2007).

\section{Fase 4: A Transcrição dos Depoimentos}

Se comparadas com as entrevistas presenciais, as entrevistas on-line certamente tomam muito mais tempo. Este tempo extra, no entanto, é amplamente compensado pelo fato de que os depoimentos dos entrevistados não precisam ser transcritos. Podem ser salvos na íntegra, da maneira mais fiel possível sem qualquer risco de edição ou má interpretação. Ao clicar em "salvar", cada conversa pode ser transformada em um arquivo de texto e salva em uma única pasta ou em pastas distintas pelo entrevistador.

Os discursos gravados apresentam, no entanto, características que os tornam difíceis de ler com os objetivos das análises previstas pelo MEDS. Para começar, muitos dos apelidos (nicks) dos entrevistados, que aparecem cada vez que dizem alguma coisa (e dão um enter), são extremamente longos e complexos porque se tornaram um canal de expressão de sentimentos, dúvidas, indignações, desejos, etc. Tais nicks atrapalham muito a leitura. Segue-se o exemplo do um trecho inicial de uma entrevista, no qual é difícil distinguir o que está sendo dito pelo entrevistado:

[b]***LuLuZinhA*** Em Oração Por Um Amigo ... Força CaReCa !!! [/b] diz

pode fazer a entrevista

Fer diz: oba!!!!!!!!!!!!!!!!!!!!!!!!!!!!!!!!!!!!!!!!!!!!!!!!!!!!!! $[\mathrm{b}]^{* * *}$ LuLuZinhA*** Em Oração Por Um Amigo ... Força $\mathrm{CaReCa}$ !!! [/b] diz:

olha lá nas perguntas hein 
$[\mathrm{b}]^{* * *}$ LuLuZinhA*** Em Oração Por Um Amigo ... Força CaReCa !!! [/b] diz:

hehe

Fer diz: hahahahahahahahahahaha

Fer diz: são perguntas sérias, eu prometo

Em segundo lugar, os depoimentos são muito entrecortados e, se o entrevistador não for muito cuidadoso, sempre pode haver um ou outro caso de falta de sincronia entre pergunta e resposta. É, portanto, aconselhável que, sem que haja qualquer edição das falas dos entrevistados, os depoimentos sejam tornados mais facilmente legíveis para submissão aos processos de análise previstos pelo MEDS (os longos nicks, por exemplo, podem ser substituídos por formas abreviadas ou por nomes fictícios curtos.)

\section{Fase 5: A Análise dos Depoimentos Coletados}

Considerações Gerais. As análises do MEDS são levadas a cabo do mesmo modo, independentemente de os dados terem sido coletados presencialmente ou on-line. No que se segue serão destacados seus pontos principais.

Tanto no caso dos depoimentos coletados presencialmente quanto no caso daqueles coletados on-line, o MEDS tem como objetivo sua interpretação e não a verificação de hipóteses. No campo da pesquisa qualitativa em geral (Nicolaci-da-Costa, 2007; Taylor, 2001; Turato, 2003), essa interpretação, pode ser realizada a partir de duas abordagens diferentes: (a) a abordagem êmica, cujo ponto de partida são as categorias que emergem dos pronunciamentos dos entrevistados; e (b) a abordagem ética, que parte de categorias prévias oriundas das teorias que servem de base à pesquisa. O MEDS privilegia a abordagem êmica em ambos os tipos de coleta de dados.

Também à semelhança do que acontece quando as entrevistas são presenciais, a interpretação dos depoimentos coletados baseia-se na identificação de regularidades, padrões e outros aspectos recorrentes (tanto é que, na maior parte das vezes, a coleta de dados é considerada suficiente quando atinge o já discutido "ponto de saturação").

A Análise Propriamente Dita. A análise do MEDS é realizada em duas etapas complementares. A primeira, chamada de inter-participantes, consiste na análise das respostas dadas pelo grupo como um todo, enquanto a segunda, denominada intra-participantes, se dedica à análise detalhada de cada uma das entrevistas individuais.

$\mathrm{Na}$ etapa inter-participantes, dado que os entrevistados têm um perfil homogêneo e se pronunciam sobre todos os itens do roteiro, as respostas são sistematicamente comparadas em busca de recorrências. Dessas recorrências, por sua vez, emergem categorias - sempre êmicas - que dão visibilidade aos valores do grupo ao qual os entrevistados pertencem. A análise inter-participantes tem também o importante papel de fornecer ao pesquisador uma visão geral dos resultados obtidos, visão essa que será aprofundada na análise das entrevistas individuais.

$\mathrm{Na}$ etapa intra-participantes, que é uma das características distintivas do MEDS (Nicolaci-da-Costa, 2007), é realizada uma análise sistemática das respostas indi- viduais, na qual são feitas comparações internas aos depoimentos de cada um dos entrevistados. Estas comparações buscam inconsistências, contradições, novos conceitos, novos usos de linguagem, etc. no discurso de cada um dos participantes.

É no entrecruzamento das análises efetuadas nessas duas etapas que pode ser melhor avaliada a importância da ênfase dada pelo MEDS à informalidade, à descontração e aos demais procedimentos que têm por finalidade fazer com que os entrevistados se sintam livres para se pronunciar como bem entenderem. Essa liberdade de expressão não pode ser subestimada. Tanto em sua versão presencial quanto em sua versão on-line, ela é fundamental para que possa emergir aquilo que o pesquisador não pode prever e deseja conhecer. É também imprescindível para que, quando relevante, uma das características do roteiro do MEDS - o contraste entre respostas abstratas e concretas - revele inconsistências e/ou contradições que facultam o acesso ao discurso subjacente (Nicolaci-da-Costa, 2007).

\section{Conclusão}

Há quatro décadas, para contestar resultados produzidos por estudos em que adolescentes negros tinham seu desempenho verbal e intelectual avaliados em contextos estranhos ao seu de origem, o lingüista William Labov ousou inovar. Sua inovação teve resultados importantes em duas áreas diferentes. Em primeiro lugar, mostrou de forma irrefutável o quanto havia de preconceito nos discursos supostamente baseados em dados científicos que sustentavam as práticas discriminatórias e segregacionistas da época. Em segundo lugar, erigiu a conversa informal cotidiana em contextos também cotidianos e igualmente informais como o modelo para entrevistas que tenham por finalidade apreender, da forma menos contaminada possível, os valores, a língua, a visão de mundo, os modos de sentir ou de se relacionar com os outros, etc. daqueles que entrevistamos. Tal postura marcou época e influenciou toda uma geração de pesquisadores (Nicolaci-da-Costa, 1987).

Nos anos que se seguiram à publicação de "The logic of non-standard English", houve muitas mudanças no campo das pesquisas em ciências humanas e sociais. No que diz respeito às entrevistas presenciais, à influência do trabalho de Labov se somaram outras (em grande parte oriundas da antropologia) e passou a ser grande a preocupação dos pesquisadores que usam métodos qualitativos com os procedimentos que dão às suas entrevistas o clima de uma conversa natural. Entre estes, a escolha do(s) local(locais) no(s) qual(quais) essas entrevistas são realizadas é vista como bastante nevrálgica (tanto que, em muitos métodos, o próprio entrevistado é solicitado a escolher onde quer que a entrevista seja conduzida - Nicolaci-da-Costa, 2007).

Mais recentemente, no entanto, nos deparamos com uma surpresa que alterou radicalmente a noção do que pode ser definido como um lugar de conversação informal. Com o advento da difusão da Internet, muitas das conversas cotidianas migraram para ambientes on-line (nos quais, como 
Nicolaci-da-Costa, A. M., Romão-Dias, D. \& Di Luccio, F. (2009). Uso de Entrevistas On-Line no Método de Explicitação do Discurso Subjacente (MEDS).

vimos, a conversa ocorre por escrito em tempo real), ambientes esses - como o ICQ, o MSN Messenger, o Google Talk e congêneres - que se tornaram cada vez mais atraentes e freqüentados. Tal migração, a nosso ver, justifica que a conversa informal digitada on-line seja tomada como modelo para entrevistas igualmente informais e igualmente digitadas on-line nos ambientes nos quais elas comumente ocorrem.

É claro que, como discutido anteriormente, as entrevistas on-line não vieram substituir as entrevistas presenciais em todos os casos. Reiteramos aqui o que afirmamos repetidas vezes ao longo deste artigo: a adequação de um ou outro tipo de entrevista é ditada pelos objetivos do pesquisador na investigação que realiza. É, no entanto, importante que as entrevistas on-line sejam encaradas como uma alternativa séria e viável para a coleta de dados. Nosso intuito neste trabalho foi, portanto, o de, dentro do escopo do Método de Explicitação do Discurso Subjacente (MEDS), apresentar essa nova opção aos nossos leitores, apontando suas especificidades, requisitos, vantagens e desvantagens bem como revelando o histórico, os raciocínios e as necessidades que a legitimam.

\section{Referências}

Abreu, R. S., \& Nicolaci-da-Costa, A. M. (2006). Mudanças geradas pela Internet no cotidiano escolar: As reações dos professores. Paidéia, 16(34), 193-203.

Bertaux, D. (1980). L'approche biographique: sa validité méthodologique, ses potentialités. Cahiers Internationaux de Sociologie, 59, 197-225.

Crystal, D. (2006). Language and the internet. Cambridge, MA: Cambridge University Press.

Denzin, N. K., \& Lincoln, Y. S. (2000). Introduction: The discipline and practice of qualitative research. In N. K. Denzin \& Y. S. Lincoln (Eds.), Handbook of qualitative research (2. ed., pp. 1-28). Thousand Oaks, CA: Sage.

Di Luccio, F., \& Nicolaci-da-Costa, A. M. (2007). Hipertexto, blogs e leitores-escritores. In M. Rettenmaier \& T. M. K. Rösing (Eds.), Questões de leitura no hipertexto (pp. 92-110). Passo Fundo, RS: Universidade de Passo Fundo Editora.

Gomes, W. (1997). A entrevista fenomenológica e o estudo da experiência consciente. Psicologia USP, 8(2), 305-336.

Jodelet, D. (2003). Aperçus sur les methodologies qualitatives. In S. Moscovici \& F. Buschini (Eds.), Les méthodes des sciences humaines (pp. 139-161). Paris: PUF.

Labov, W. (1972). The logic of non-standard English. In W. Labov, Language in the inner city: Studies in the Black English Vernacular. Philadelphia, PA: University of Pennsylvania Press.

Maxwell, J. A. (2005). Qualitative research design: An interactive approach (2. ed.). Thousand Oaks, CA: Sage.

Nicolaci-da-Costa, A. M. (1987). Sujeito e cotidiano: Um estudo da dimensão psicológica do social. Rio de Janeiro, RJ: Campus.

Nicolaci-da-Costa, A. M. (1998). Na malha da rede: Os impactos íntimos da internet. Rio de Janeiro, RJ: Campus.

Nicolaci-da-Costa, A. M. (2007). O campo da pesquisa qualitativa e o Método de Explicitação do Discurso Subjacente (MEDS). Psicologia: Reflexão e Crítica, 20(1), 65-73.
Ramalho, E. F. (2005). Par perfeito: Um novo espaço virtual para a procura de parceiros amorosos. Dissertação de Mestrado não-publicada, Departamento de Psicologia, Pontifícia Universidade Católica do Rio de Janeiro, RJ.

Rocha-Coutinho, M. L. (1994). Tecendo por trás dos panos: A mulher brasileira nas relações familiares. Rio de Janeiro, RJ: Rocco.

Romão-Dias, D., \& Nicolaci-da-Costa, A. M. (2005). Eu posso me ver como sendo dois, três ou mais: Algumas reflexões sobre a subjetividade contemporânea. Psicologia: Ciência e Profissão, 25(1), 70-87.

Rubin, H. J., \& Rubin, I. S. (2005). Qualitative interviewing: The art of hearing data (2. ed.). Thousand Oaks, CA: Sage.

Seidman, I. (1998). Interviewing as qualitative research: A guide for researchers in education and the social sciences (2. ed.). New York: Teachers College Press.

Taylor, S. (2001). Locating and conducting discourse analytic research. In M. Wetherell, S. Taylor, \& S. J. Yates (Eds.), Discourse as data: A guide for analysis (pp. 5-48). London: Sage.

Turato, E. R. (2003). Tratado da metodologia da pesquisa clínico-qualitativa. Petrópolis, RJ: Vozes.

Weiss, R. S. (1994). Learning from strangers: The art and method of qualitative interview studies. New York: The Free Press.
Recebido: 03/04/2008 $1^{a}$ revisão: $15 / 08 / 2008$ Aceite final: $21 / 08 / 2008$ 